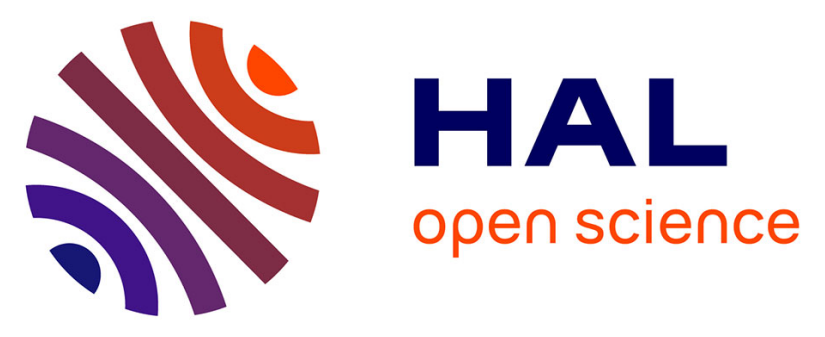

\title{
Tuning the Stability of Pd(IV) Intermediates Using a Redox Non-innocent Ligand Combined with an Organolanthanide Fragment
}

Violaine Goudy, Arnaud Jaoul, Marie Cordier, Carine Clavaguera, Grégory Nocton

\section{To cite this version:}

Violaine Goudy, Arnaud Jaoul, Marie Cordier, Carine Clavaguera, Grégory Nocton. Tuning the Stability of $\mathrm{Pd}(\mathrm{IV})$ Intermediates Using a Redox Non-innocent Ligand Combined with an Organolanthanide Fragment. Journal of the American Chemical Society, 2017, 139 (31), pp.10633-10636. 10.1021/jacs.7b05634 . hal-01999550

\section{HAL Id: hal-01999550 https://hal.science/hal-01999550}

Submitted on 29 Apr 2019

HAL is a multi-disciplinary open access archive for the deposit and dissemination of scientific research documents, whether they are published or not. The documents may come from teaching and research institutions in France or abroad, or from public or private research centers.
L'archive ouverte pluridisciplinaire HAL, est destinée au dépôt et à la diffusion de documents scientifiques de niveau recherche, publiés ou non, émanant des établissements d'enseignement et de recherche français ou étrangers, des laboratoires publics ou privés.

\section{(ㅇ)(1) $\$$}

Distributed under a Creative Commons Attribution - NonCommercial - NoDerivatives| 4.0 


\title{
Tuning the Stability of Pd(IV) Intermediates Using a Redox Non- innocent Ligand Combined with an Organolanthanide Fragment
}

\author{
Violaine Goudy, ${ }^{\dagger}$ Arnaud Jaoul, ${ }^{\dagger}$ Marie Cordier, ${ }^{\dagger}$ Carine Clavaguéra, ${ }^{\ddagger 0}$ and Grégory Nocton*, ${ }^{\dagger}$ \\ ${ }^{\dagger}$ LCM, CNRS, Ecole polytechnique, Université Paris-Saclay, Route de Saclay, 91128 Palaiseau Cedex, France \\ ${ }^{\ddagger}$ Laboratoire de Chimie Physique, CNRS - Université Paris-Sud, Université Paris-Saclay, 15 avenue Jean Perrin, 91405 Orsay Cedex, \\ France
}

Supporting Information

ABSTRACT: The unique combination of a divalent organolanthanide fragment, $\mathrm{Cp}{ }_{2} \mathrm{Yb}$, with bipyrimidine (bipym) and a palladium bis-alkyl fragment, $\mathrm{PdMe}_{2}$, allows the rapid formation and stabilization of a $\mathrm{Pd}^{\mathrm{IV}}$ tris-alkyl moiety after oxidative addition with MeI. The crucial role of the organolanthanide fragment is demonstrated by the substitution of bipym by the 4,5,9,10-tetraazaphenanthrene ligand, which drastically modifies the electronic structure and tunes the stability of the $\mathrm{Pd}^{\mathrm{IV}}$ species.

$\mathrm{W}$ hile organometallic complexes of $\mathrm{Pd}^{\mathrm{IV}}$ and $\mathrm{Pt}^{\mathrm{IV}}$ have been known for several decades, ${ }^{1}$ the expansion of their utility in organic synthesis urges the chemical community to improve or find new methods that allow the easy access of high oxidation intermediates of the late transition metals, such as $\mathrm{Pd}^{\mathrm{III}}, 2 \mathrm{Pd}^{\mathrm{IV}}, 1,3$ $\mathrm{Ni}^{\mathrm{IV}},{ }^{4} \mathrm{Ni}^{\mathrm{III}}, 5$ and $\mathrm{Cu}^{\mathrm{III}} .6$. Besides, there is a growing debate in the scientific community about the electronic structure of these highvalent intermediates, ${ }^{6 a, 7}$ and more examples of well-characterized compounds are required to address accurately their chemical nature.

The first occurrence of isolated organometallic $\mathrm{Pd}^{\mathrm{IV}}$ complexes appeared in 1975, with the oxidation by chlorine of a series of palladium bis- $\mathrm{C}_{6} \mathrm{~F}_{5}$ complexes coordinated by different chelates. ${ }^{8}$ A decade later, Canty reported the oxidative addition of dimethylpalladium complexes bearing bipyridine and phenanthroline ligands, leading to complexes of $\mathrm{Pd}^{\mathrm{IV}}$ that were stable enough for isolation. ${ }^{9}$ This seminal work largely developed this area, and other tris-methyl complexes of $\mathrm{Pd}^{\mathrm{IV}}$ appeared. ${ }^{1,10}$ Since these developments, their formation mechanism and relative stability have been studied with high interest. Therein, the chelate ligand is crucial, because of its geometric (ligand symmetry, ${ }^{10,11}$ rigidity, ${ }^{12}$ dynamic coordination $)^{13}$ or electronic (vide infra) role. As such, the fine-tuning of the ligand that allows the stabilization of various reactive intermediates is needed to develop novel reactions.

Recent detailed reports by Bergman and Tilley showed that the coordination of a Lewis acid in the platinum bipyrazine $(\text { bpyz })^{14}$ and platinum bipyrimidine (bipym) $)^{15}$ bis-aryl complexes leads to a dramatic acceleration of the biaryl reductive elimination, implementing an electronic remote control strategy to manipulate the stability and reactivity of group 10 organometallics using bimodal ligands. Van der Vlugt et al. reported another strategy based on the tuning of non-innocent ligands, allowing intramolecular electron transfer(s), to achieve homo-
Scheme 1. Synthetic Scheme of the Compounds 1-4

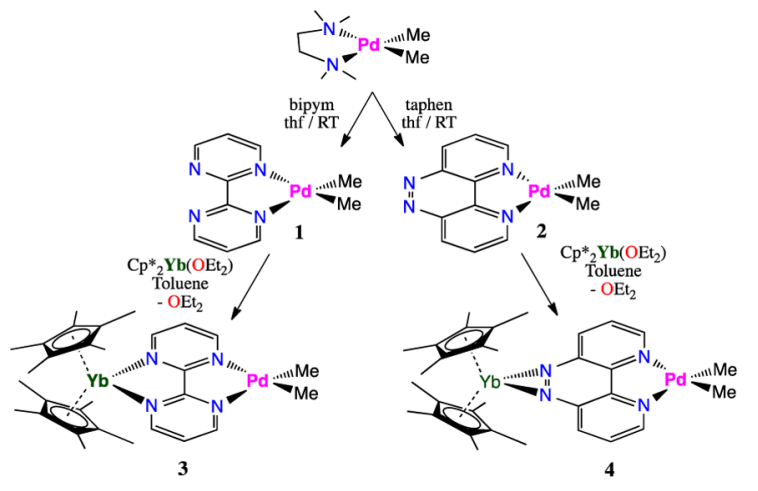

lytic bond cleavage ${ }^{16}$ and radical reactivity at a $\mathrm{Pd}^{\mathrm{II}}$ metal center, ${ }^{17}$ instead of the usual two-electron reactivity.

In this context, the comprehensive electronic studies made on different $\mathrm{N}$-heterocyclic adducts of divalent lanthanides ${ }^{18}$ demonstrated that their ground state is the result of multiple factors. Thus, $\mathrm{Cp}_{2}{ }_{2} \mathrm{Yb}$ (bipy) is a multi-configurational singlet composed of an open-shell $\left(\mathrm{f}^{13}, \mathrm{~L}^{\bullet-}\right)$ and a closed-shell $\left(\mathrm{f}^{14}, \mathrm{~L}^{0}\right)$ state in a 0.83:0.17 ratio, ${ }^{18 \mathrm{~b}}$ while $\mathrm{Cp} *{ }_{2} \mathrm{Yb}$ (phen) is a triplet state $\left(\mathrm{f}^{13}, \mathrm{~L}^{\bullet-}\right){ }^{18 \mathrm{c}}$ A chemical ramification of these observations is that the bipy adduct is stable while the phen adduct dimerizes, featuring a reversible $\mathrm{C}-\mathrm{C}$ bond. ${ }^{18 \mathrm{c}, \mathrm{j}}$ This dichotomy was rationalized by the symmetry of the molecular orbital of the ligand ( $C_{2 v}$ symmetry) that is getting populated: the $\mathrm{b}_{1}$ orbital in the bipy complex has large coefficients on the $\mathrm{N}$-atoms, allowing for easy magnetic communication. In contrast, the $a_{2}$ one in the phen complex has small coefficients on the $\mathrm{N}$-atoms, discouraging magnetic communication. ${ }^{18 \mathrm{c}}$

Knowing this, we thought it would be possible to tune the relative stability of group 10 organometallics using organolanthanides bearing different redox non-innocent ligands. In this Communication, we wish to present the synthesis and chemical structure analysis of a new type of organometallics that combine a divalent lanthanide, $\mathrm{Cp}{ }_{2} \mathrm{Yb}$, and a transition metal, $\mathrm{PdMe}_{2}$, bridged by redox non-innocent ligands, bipym and 4,5,9,10tetraazaphenanthrene (taphen), as the analogues of bipy and phen. The formation and stabilization of a $\mathrm{Pd}^{\mathrm{IV}}$ tris-alkyl moiety is discussed as a proof of concept.

Received: May 31, 2017

Published: July 25, 2017 


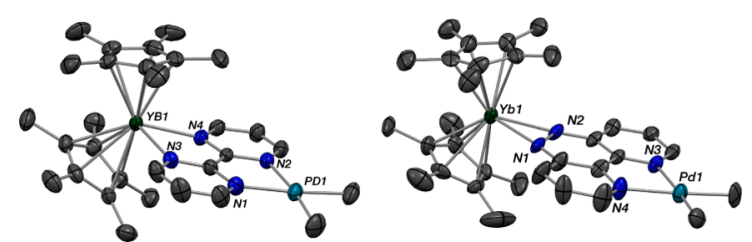

Figure 1. ORTEP drawings of 3 and 4 . Thermal ellipsoids are set at 50\% probability level; $\mathrm{H}$-atoms have been removed for clarity.

The bipym and the taphen bis-methylpalladium complexes, (bipym) $\mathrm{PdMe}_{2}$ (1) and (taphen) $\mathrm{PdMe}_{2}$ (2), were synthesized from (tmeda) $\mathrm{PdMe}_{2}$ in thf (Scheme 1). Both complexes produced red needles suitable for X-ray diffraction (XRD) analysis (see Supporting Information (SI)). Complexes 1 and $\mathbf{2}$ were combined with $\mathrm{Cp}^{*}{ }_{2} \mathrm{Yb}\left(\mathrm{OEt}_{2}\right)^{19}$ in toluene to yield the heterobimetallic complexes $\mathrm{Cp}_{2}{ }_{2} \mathrm{Yb}\left(\right.$ bipym) $\mathrm{PdMe}_{2}$ (3) and $\mathrm{Cp}^{*}{ }_{2} \mathrm{Yb}$ (taphen) $\mathrm{PdMe}_{2}$ (4), respectively. Both 3 and 4 are dark toluene solutions from which dark brown blocks of 3 and dark purple needles of 4 , suitable for XRD studies, were isolated (Figure 1).

The $\mathrm{Cp} *-\mathrm{Yb}$ average distances in $\mathbf{3}$ and $\mathbf{4}$ are similar (2.305(8) and 2.29(1) $\AA$, respectively) and are indicative of the oxidation state of the $\mathrm{Yb}$ center. Typical values of $2.30-2.31 \AA$ are observed for $\mathrm{Yb}^{\mathrm{III}}$, ${ }^{18 \mathrm{~g}}$ whereas longer $\mathrm{Cp} *-\mathrm{Yb}$ distances $(2.43-2.50 \AA)$ are indicative of $\mathrm{Yb}^{\mathrm{II}}$ complexes. ${ }^{20}$ They oscillate between these limiting values when the electronic ground state is multiconfigurational. ${ }^{8 \mathrm{a}, \mathrm{b}}$ Within this picture, the $\mathrm{Cp}^{*}-\mathrm{Yb}$ distances in 3 and $\mathbf{4}$ would better agree with $\mathrm{Yb}^{\mathrm{III}}$ complexes. This means that an electron has been transferred to the ligand. In 3 , this can be further noticed by comparing the $\mathrm{C}-\mathrm{C}$ distance that links the two pyrimidine heterocycles with that of the neutral bipym in 1: $1.417(2)$ vs $1.491(6) \AA$, respectively. ${ }^{21}$ A reduced distance is indicative of a ligand-based reduction, as noted in the recent work of Wieghardt et al. ${ }^{22}$ In comparison, the monoreduced bipy ligand features an average short $\mathrm{C}-\mathrm{C}$ distance of $1.42(1) \AA^{18 a, b, g, 23}$ In 4, a similar trend is observed when comparing the diazo distance in $2(1.295(5) \AA)$ and that in 4 (1.38(1) $\AA$ ). An increased distance is indicative of a reduction. The Pd-N(ave) and Pd-C(ave) distances in 3 (2.129(4) and 2.022(3) $\AA$ ) and 4 (2.174(4) and 1.990(3) $\AA$ ) are comparable than those in $1(2.135(5)$ and 2.028(5) $\AA$ ) and 2 (2.152(5) and $2.028(8) \AA$ ), indicating that the coordination environment of the $\mathrm{Pd}$ center is only slightly affected by the lanthanide coordination.

${ }^{1} \mathrm{H}$ NMR spectra of 3 and 4 were recorded in toluene- $d_{8}$ and are consistent with $C_{2 v}$-symmetric species with three bipym (taphen) proton shifts of 256.3 (73.9), $-3.97(-135.1)$, and -159.4 (-295.7) ppm, one Cp* methyl shift of 5.91 (13.44) ppm, and one palladium methyl shift of $6.03(-8.46) \mathrm{ppm}$. Since the signals are largely shifted in both cases compared to usual diamagnetic positions, the ${ }^{1} \mathrm{H}$ NMR data are in agreement with an oxidized $\mathrm{Yb}$ center and thus a reduced $\mathrm{LPdMe}_{2}$ fragment $(\mathrm{L}=$ bipym, taphen). The variable-temperature NMR of $\mathbf{4}$ revealed a Curie behavior (linear $\delta$ vs $1 / T$ plot over the -80 to $60{ }^{\circ} \mathrm{C}$ temperature range, see SI, Figure S7).

Temperature-dependent magnetic data were recorded in the $2-300 \mathrm{~K}$ temperature range (Figure 2 ). The $\chi T$ values at room temperature (RT) are 2.28 and $2.62 \mathrm{emu} \cdot \mathrm{K} \cdot \mathrm{mol}^{-1}$ for 3 and $\mathbf{4}$, respectively. The related $\mathrm{Cp}^{*}{ }_{2} \mathrm{Yb}$ (phen) and $\mathrm{Cp} *{ }_{2} \mathrm{Yb}$ (bipy) complexes have a $\chi T$ values of 2.36 (triplet) and $0.72 \mathrm{emu} \cdot \mathrm{mol}^{-1}$. $\mathrm{K}$ (singlet), respectively, at $300 \mathrm{~K}^{24} \mathrm{In} 3$ and 4 , the net $\chi T$ value at $\mathrm{RT}$ is thus in better agreement with a triplet state that is significantly populated at RT. For 4, when the temperature

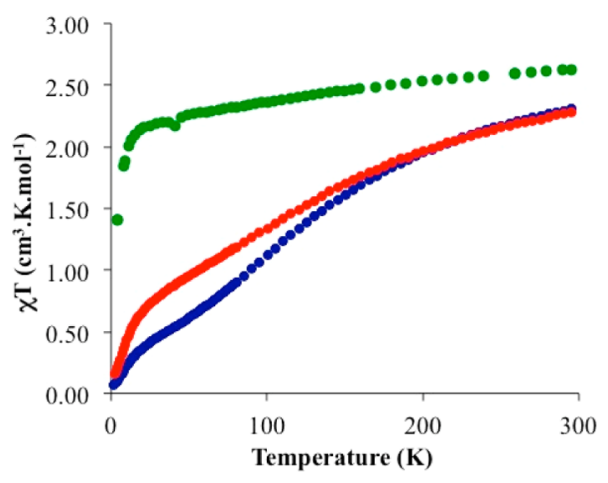

Figure 2. $\chi T$ vs $T$ plots for 3 (blue), 4 (green), and 8 (red).

decreases, the $\chi T$ value monotonously decreases to $2.10 \mathrm{emu}$. $\mathrm{mol}^{-1} \cdot \mathrm{K}$ at $15 \mathrm{~K}$ and then drops to $1.4 \mathrm{emu} \cdot \mathrm{mol}^{-1} \cdot \mathrm{K}$ at $4 \mathrm{~K}$. This behavior is typical for $\mathrm{Yb}$ complexes and is attributed to the depopulation of the crystal field states: the overall magnetic data of 4 are in agreement with a triplet ground state $(S=1) .{ }^{18 \mathrm{c}}$ The situation found in 3 is drastically different. The $\chi T$ value decreases faster with decreasing temperature until a first inflection point around $50 \mathrm{~K}$ and a second one at $15 \mathrm{~K}$. This behavior was already reported for $\mathrm{Cp}^{*}{ }_{2} \mathrm{Yb}(\mathrm{L})$ complexes ${ }^{18 \mathrm{~b}, \mathrm{f}, \mathrm{h}}$ and may be explained as follows: (i) At low temperature, the ground state is an open-shell singlet ground state $\left(\mathrm{f}^{13}, \mathrm{~L}^{\bullet-}\right)$ mixed with a closed-shell singlet $\left(\mathrm{f}^{14}, \mathrm{~L}^{0}\right)$; the ground state is multiconfigurational, and the magnetic susceptibility is temperature independent. (ii) The inflection point at $15 \mathrm{~K}$ indicates the presence of a second open-shell singlet ground state with a different ratio of open-shell vs closed-shell; while the temperature increases, this low-lying state is getting populated (Boltzmann). ${ }^{18 \mathrm{~b}}$ The presence of the two low-lying singlet states is in good agreement with two similar $b_{1}$ LUMO and LUMO+1 orbitals in $\mathbf{1}$ (see SI, Figure S29). (iii) The inflection point at $50 \mathrm{~K}$ indicates the temperature at which the triplet state $(S=1)$ is getting populated up to RT. ${ }^{25}$ The relative energy of the triplet-singlet gap can be qualitatively estimated from the $\chi T$ value at RT $\left(300 \mathrm{~cm}^{-1}\right.$, SI, Figure S14).

The magnetic studies and NMR data agree well with different electronic ground states for 3 and $\mathbf{4}$. In $\mathbf{4}$, the electron is lying on the ligand with little participation of the $\mathrm{Yb}$ metal center, while in 3 , a multi-configuration state is present and the $\mathrm{Yb}$ metal center has a strong influence on the electron located on the ligand. The next step is to understand how it may affect the reactivity at the Pd center: this strong contrast noted between $\mathbf{3}$ and $\mathbf{4}$ may allow tuning the stability of $\mathrm{Pd}^{\mathrm{IV}}$ intermediates. A simple oxidative addition has been performed to test this conjecture.

The oxidative additions of $\mathbf{1}$ and $\mathbf{2}$ by MeI were followed by ${ }^{1} \mathrm{H}$ NMR in toluene- $d_{8}$ and thf- $d_{8}$ for solubility reasons. In agreement with Canty's previous experiments, ${ }^{9 a, b, d}$ the oxidative addition is rather slow at RT (SI, Table S1). For $\mathbf{1}$ and 2, the reductive elimination is fast and starts when the $\mathrm{Pd}^{\mathrm{IV}}$ intermediate is not entirely formed (SI, Table S2). ${ }^{26}$ When studied on the isolated $\mathrm{Pd}^{\mathrm{IV}}$ complexes, the reductive elimination is fast as well in both cases (see SI, Figures S16-S23 and Tables S1 and S2, for details).

The reaction of 1 equiv of MeI with 4 at RT in toluene- $d_{8}$ (Scheme 2) leads to a slight change of color from dark red to brown, accompanied by precipitation of a dark powder. ${ }^{1} \mathrm{H}$ NMR analysis of the product performed several minutes after the reaction indicates the presence of several species whose ratio changes over time and the characteristic ${ }^{1} \mathrm{H}$ NMR singlet of 


\section{Scheme 2. Oxidative Addition of 4 with MeI}

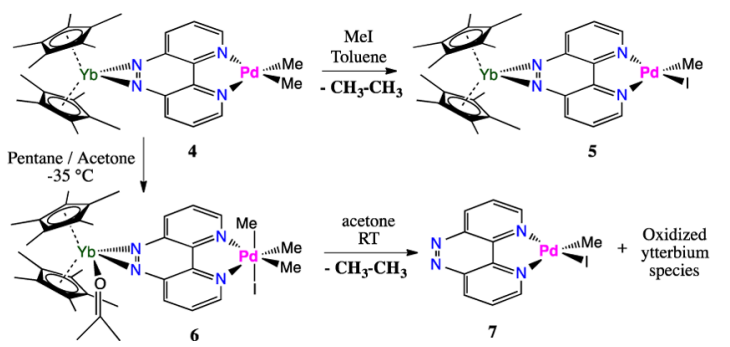

ethane at $0.9 \mathrm{ppm}$. The ${ }^{1} \mathrm{H}$ NMR spectrum evolves to an unsymmetrical clean complex, 5. Performing the reaction in a cold pentane/acetone mixture at $-40{ }^{\circ} \mathrm{C}$ leads to the formation of black blocks of the $\mathrm{Cp}{ }_{2}{ }_{2} \mathrm{Yb}\left(\mathrm{OCMe}_{2}\right)$ (taphen) PdIMe intermediate, 6, suitable for XRD analysis. Following the reductive elimination of 6 in an acetone- $d_{6}$ solution by ${ }^{1} \mathrm{H}$ NMR at RT reveals only the formation of ethane and further crystallization of 7 (see SI, Figures S26 and S37, for ${ }^{1} \mathrm{H}$ NMR and ORTEP of 7).

On the other hand, the reaction of 3 with MeI in the same conditions (RT in toluene- $d_{8}$, Scheme 3 ) leads to the fast and clean conversion into the $\mathrm{Cp}_{2}{ }_{2} \mathrm{Yb}$ (bipym) $\mathrm{PdIMe}_{3}, 8$ (Figure 3). The latter complex crystallizes in toluene- $d_{8}$ at low temperature and yields XRD-suitable brown needles. The oxidative addition is dramatically accelerated by the electron transfer and allows a clean synthesis of a stable tris-alkyl $\mathrm{Pd}^{\mathrm{IV}}$.

\section{Scheme 3. Oxidative Addition of 3 with MeI}
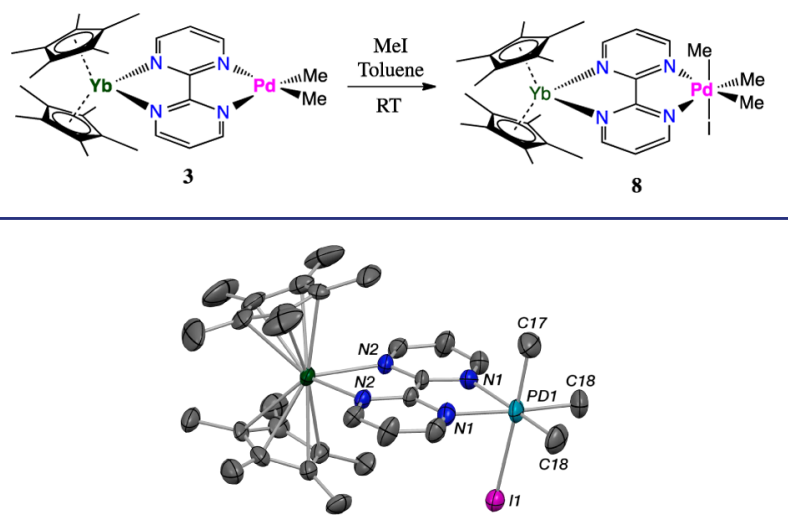

Figure 3. ORTEP drawing of 8 . Thermal ellipsoids are set at 50\% probability level; $\mathrm{H}$-atoms have been removed for clarity.

The $\mathrm{Cp} *-\mathrm{Yb}$ distances are $2.293 \AA$ and are slightly shorter than that of 4, while the $\mathrm{Yb}-\mathrm{N}$ (ave) distances of 2.359(5) $\AA$ are comparable to that of 4 . The Pd center is hexa-coordinated, with three facial methyl ligands, two $\mathrm{N}$-atoms of the bipym ligand, and one I-atom. The distances around the metal center are very similar to those in the fac-(bipy)PdIMe $\mathrm{P}_{3}$ complex, in which the $\mathrm{Pd}-\mathrm{C}($ ave), $\mathrm{Pd}-\mathrm{N}$ (ave), and $\mathrm{Pd}-\mathrm{I}$ distances are 2.040(4), 2.181(11), and 2.834(1) $\AA$, respectively, ${ }^{9 a, d}$ with the exception of the Pd-I distance that is $0.05 \AA$ shorter. The geometry and metric parameters compare well with those of intermediate 6 (see SI, Tables S9 and S11). Interestingly, the C-C distance that links the two pyrimidine heterocycles is very short, i.e., 1.35(1) $\AA$, establishing a strongly localized $\pi$ electron density on this particular bond, in agreement with the population of $a b_{1}$ orbital (LUMO in SI, Figure S30).
The ${ }^{1} \mathrm{H}$ NMR spectrum of 8 in toluene- $d_{8}$ reveals three bipym protons at 264.5, 4.70, and $-168.4 \mathrm{ppm}$, close to the values for 3 , in agreement with a similar structure and electronic structure. Two additional signals are present for the methyl groups in a 2:1 ratio, and the $\mathrm{Cp}^{*}$ has two resonances (5.99 and $6.34 \mathrm{ppm}$ ), in agreement with a $C_{s}$ symmetry and indicative of the presence of a bonded I-atom in solution on the NMR time scale. This contrasts with Canty's findings that the cationic form of the complex is the key for the reductive elimination to occur. ${ }^{9 \mathrm{c}}$ The spectra were very similar in coordinating solvents such as thf- $d_{8}$ and pyridine$d_{5}$. Addition of $\mathrm{CD}_{3} \mathrm{I}$ to 3 leads to a scrambling of the deuterated methyl positions, even when the reaction is performed at low temperature. This can be explained by a possible alkyl halide exchange in these complexes during the oxidative addition. ${ }^{27}$ The oxidative addition has also been performed with MeOTf, and it only resulted in fast reductive elimination (SI, Figure S28), which is indicative of the importance of the $\mathrm{Pd}-\mathrm{I}$ coordination in the $\mathrm{Pd}^{\mathrm{IV}}$ stability.

The clean and fast synthesis of $\mathbf{8}$ allows its crystallization in a pure form. We took advantage of this to study the kinetics of the reductive elimination process to understand the influence of the organolanthanide fragment. These studies were performed in toluene- $d_{8}$, a non-coordinating and non-dissociative solvent, and showed first-order kinetics. A satisfactory Eyring plot was obtained between 10 and $30{ }^{\circ} \mathrm{C}$ (Figure 4), revealing $\Delta H^{\ddagger}=$

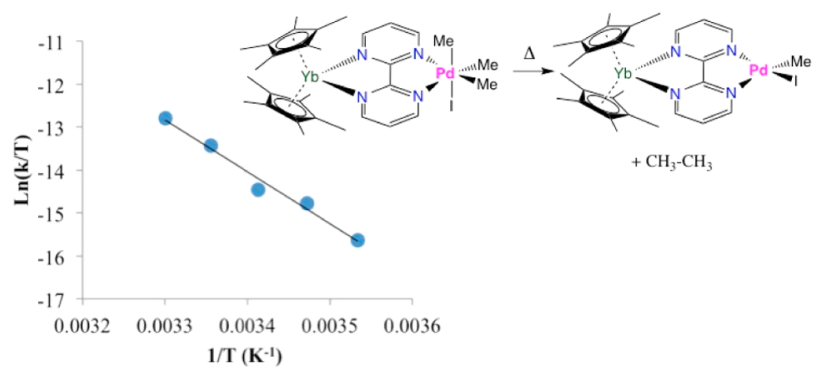

Figure 4. Eyring plot of the reductive elimination of 8 .

24(1) $\mathrm{kcal} \cdot \mathrm{mol}^{-1}$ and $\Delta S^{\ddagger}=6(6) \mathrm{cal} \cdot \mathrm{mol}^{-1} \cdot \mathrm{K}^{-1}$. The $\Delta H^{\ddagger}$ is significantly increased compared to Canty's measurements of the (bipy) $\mathrm{PdMe}_{2}$ complex in several different solvents (from 8.4 to $\left.18.6 \mathrm{kcal} \cdot \mathrm{mol}^{-1}\right) .^{9 \mathrm{c}}$ Thus, it seems that the mechanism of the reductive elimination is not modified compared to that reported earlier, but the barrier is increased because of a better stability of the octahedral tris-methylpalladium complex that is due to the presence of the lanthanide fragment. The net result of this is expressed by the half-life time of 8 being more than $1 \mathrm{~h}$ at RT, while those of 1,2 , and 4 were too fast to be measured in our hands (minutes).

Accordingly, the electronic structure of $\mathbf{8}$ was studied by solidstate magnetism and features a behavior similar to that of 3 : complex $\mathbf{8}$ is a multi-configurational singlet ground state with a triplet that is substantially populated at RT. The only notable difference is the absence of an inflection point at $50 \mathrm{~K}$, explained by the presence of a sole singlet ground state below the triplet in energy. This difference accounts for the different geometry (square planar vs octahedral) and indicates how the presence of the organolanthanide fragment may influence the electronic structure of the overall molecule, playing a role in the reactivity patterns at the transition metal center.

In summary, we have successfully synthesized molecules containing both lanthanide and reactive $\mathrm{PdMe}_{2}$ fragments with two different bridging ligands in which an electron is transferred 
from the lanthanide fragment, influencing drastically the rapidity at which the oxidative addition with MeI occurs by making the ligands more strongly donating and allowing the clean isolation of $\mathrm{Pd}^{\mathrm{IV}}$ species. The different symmetry of the LUMOs of the (L) $\mathrm{PdMe}_{2}$ fragments induces large differences in the electronic structure of the overall molecules. Complex 4 has a singlet ground state and 3 a triplet ground state. Moreover, in 3, the electron is transferred on the $b_{1}$ orbital that has significant spin density on the $\mathrm{N}$-atoms coordinated to the Pd center. These considerations have a large consequence on the relative stability of the $\mathrm{PdMe}_{3} \mathrm{I}$ fragment. This work implements an additional strategy for the fine-tuning of the formation and relative stability of high oxidation states in organometallic reactions, by modifying soundly the redox non-innocent ligand and the divalent lanthanide fragment.

\section{ASSOCIATED CONTENT}

\section{S Supporting Information}

The Supporting Information is available free of charge on the ACS Publications website at DOI: 10.1021/jacs.7b05634.

Synthetic details, ${ }^{1} \mathrm{H}$ NMR studies, magnetic data, theoretical data, and X-ray data (PDF)

X-ray crystallographic data for 1-4 and 7-10 (CIF)

\section{AUTHOR INFORMATION}

\section{Corresponding Author}

*greg.nocton@polytechnique.edu

ORCID $\odot$

Carine Clavaguéra: 0000-0001-5531-2333

Grégory Nocton: 0000-0003-0599-1176

Notes

The authors declare no competing financial interest.

\section{ACKNOWLEDGMENTS}

This project has received funding from the European Research Council (ERC) under the European Union' Horizon H2020 research program (grant agreement No. 716314). CNRS and Ecole Polytechnique are thanked for funding. V.G. is grateful to the French National Agency for the postdoc fellowship (ANR15-CE29-0019). A.J. is grateful to Ecole Polytechnique for Ph.D. fellowship. Drs. Eric Rivière and Isabelle Maurin are thanked for help with the magnetic measurements. This work was performed using HPC resources from GENCI-CINES/IDRIS (Grant 2016x2016086830).

\section{REFERENCES}

(1) Sehnal, P.; Taylor, R. J. K.; Fairlamb, I. J. S. Chem. Rev. 2010, 110, 824.

(2) Powers, D. C.; Ritter, T. Nat. Chem. 2009, 1, 302.

(3) (a) Whitfield, S. R.; Sanford, M. S. J. Am. Chem. Soc. 2007, 129, 15142. (b) Arnold, P. L.; Sanford, M. S.; Pearson, S. M. J. Am. Chem. Soc. 2009, 131, 13912. (c) Abada, E.; Zavalij, P. Y.; Vedernikov, A. N. J. Am. Chem. Soc. 2017, 139, 643. (d) Lanci, M. P.; Remy, M. S.; Kaminsky, W.; Mayer, J. M.; Sanford, M. S. J. Am. Chem. Soc. 2009, 131, 15618.

(4) (a) Camasso, N. M.; Sanford, M. S. Science 2015, 347, 1218. (b) Martinez, G. E.; Ocampo, C.; Park, Y.J.; Fout, A. R. J. Am. Chem. Soc. 2016, 138, 4290.

(5) Cao, T.-P.-A.; Nocton, G.; Ricard, L.; Le Goff, X.; Auffrant, A. Angew. Chem., Int. Ed. 2014, 53, 1368.

(6) (a) Storr, T.; Verma, P.; Pratt, R. C.; Wasinger, E. C.; Shimazaki, Y.; Stack, T. D. P. J. Am. Chem. Soc. 2008, 130, 15448. (b) Citek, C.; Gary, J. B.; Wasinger, E. C.; Stack, T. D. P. J. Am. Chem. Soc. 2015, 137, 6991.
(7) (a) Walroth, R. C.; Lukens, J. T.; MacMillan, S. N.; Finkelstein, K. D.; Lancaster, K. M. J. Am. Chem. Soc. 2016, 138, 1922. (b) Lemon, C. M.; Huynh, M.; Maher, A. G.; Anderson, B. L.; Bloch, E. D.; Powers, D. C.; Nocera, D. G. Angew. Chem., Int. Ed. 2016, 55, 2176. (c) Tomson, N. C.; Crimmin, M. R.; Petrenko, T.; Rosebrugh, L. E.; Sproules, S.; Boyd, W. C.; Bergman, R. G.; DeBeer, S.; Toste, F. D.; Wieghardt, K. J. Am. Chem. Soc. 2011, 133, 18785.

(8) Uson, R.; Fornies, J.; Navarro, R. J. Organomet. Chem. 1975, 96, 307.

(9) (a) Byers, P. K.; Canty, A. J.; Skelton, B. W.; White, A. H. J. Chem. Soc., Chem. Commun. 1986, 0, 1722. (b) Byers, P. K.; Canty, A. J. J. Chem. Soc., Chem. Commun. 1988, 639. (c) Byers, P. K.; Canty, A. J.; Crespo, M.; Puddephatt, R. J.; Scott, J. D. Organometallics 1988, 7, 1363. (d) Byers, P. K.; Canty, A. J.; Skelton, B. W.; White, A. H. Organometallics 1990, 9, 826.

(10) Sobanov, A. A.; Vedernikov, A. N.; Dyker, G.; Solomonov, B. N. Mendeleev Commun. 2002, 12, 14.

(11) Bennett, M. A.; Canty, A. J.; Felixberger, J. K.; Rendina, L. M.; Sunderland, C.; Willis, A. C. Inorg. Chem. 1993, 32, 1951.

(12) van Asselt, R.; Rijnberg, E.; Elsevier, C. J. Organometallics 1994, 13, 706 .

(13) Furuya, T.; Benitez, D.; Tkatchouk, E.; Strom, A. E.; Tang, P.; Goddard, W. A.; Ritter, T. J. Am. Chem. Soc. 2010, 132, 3793.

(14) Liberman-Martin, A. L.; Bergman, R. G.; Tilley, T. D. J. Am. Chem. Soc. 2013, 135, 9612.

(15) Liberman-Martin, A. L.; Levine, D. S.; Liu, W.; Bergman, R. G.; Tilley, T. D. Organometallics 2016, 35, 1064.

(16) Broere, D. L. J.; Metz, L. L.; de Bruin, B.; Reek, J. N. H.; Siegler, M. A.; van der Vlugt, J. I. Angew. Chem., Int. Ed. 2015, 54, 1516.

(17) Broere, D. L. J.; de Bruin, B.; Reek, J. N. H.; Lutz, M.; Dechert, S.; van der Vlugt, J. I. J. Am. Chem. Soc. 2014, 136, 11574.

(18) (a) Booth, C. H.; Walter, M. D.; Kazhdan, D.; Hu, Y.-J.; Lukens, W. W.; Bauer, E. D.; Maron, L.; Eisenstein, O.; Andersen, R. A. J. Am. Chem. Soc. 2009, 131, 6480. (b) Booth, C. H.; Kazhdan, D.; Werkema, E. L.; Walter, M. D.; Lukens, W. W.; Bauer, E. D.; Hu, Y.-J.; Maron, L.; Eisenstein, O.; Head-Gordon, M.; Andersen, R. A. J. Am. Chem. Soc. 2010, 132, 17537. (c) Nocton, G.; Lukens, W. L.; Booth, C. H.; Rozenel, S. S.; Medling, S. A.; Maron, L.; Andersen, R. A. J. Am. Chem. Soc. 2014, 136, 8626. (d) Schultz, M.; Boncella, J. M.; Berg, D. J.; Tilley, T. D.; Andersen, R. A. Organometallics 2002, 21, 460. (e) Walter, M. D.; Berg, D. J.; Andersen, R. A. Organometallics 2006, 25, 3228. (f) Nocton, G.; Booth, C. H.; Maron, L.; Andersen, R. A. Organometallics 2013, 32, 1150. (g) Nocton, G.; Booth, C. H.; Maron, L.; Andersen, R. A. Organometallics 2013, 32, 5305. (h) Nocton, G.; Booth, C. H.; Maron, L.; Ricard, L.; Andersen, R. A. Organometallics 2014, 33, 6819. (i) Nocton, G.; Ricard, L. Dalton Trans. 2014, 43, 4380. (j) Nocton, G.; Ricard, L. Chem. Commun. 2015, 51, 3578.

(19) (a) Tilley, T. D.; Andersen, R. A.; Spencer, B.; Ruben, H.; Zalkin, A.; Templeton, D. H. Inorg. Chem. 1980, 19, 2999. (b) Tilley, T. D.; Boncella, J. M.; Berg, D. J.; Burns, C. J.; Andersen, R. A.; Lawless, G. A.; Edelman, M. A.; Lappert, M. F. In Inorganic Synthesis; Ginsberg, A. P., Ed.; John Wiley \& Sons, Inc.: New York, 1990; Vol. 27, p 146.

(20) Cheisson, T.; Auffrant, A.; Nocton, G. Organometallics 2015, 34, 5470.

(21) Jacquot, L.; Xémard, M.; Clavaguéra, C.; Nocton, G. Organometallics 2014, 33, 4100.

(22) (a) England, J.; Bill, E.; Weyhermuller, T.; Neese, F.; Atanasov, M.; Wieghardt, K. Inorg. Chem. 2015, 54, 12002. (b) Wolff, C.; Gottschlich, A.; England, J.; Wieghardt, K.; Saak, W.; Haase, D.; Beckhaus, R. Inorg. Chem. 2015, 54, 4811.

(23) Scarborough, C. C.; Wieghardt, K. Inorg. Chem. 2011, 50, 9773.

(24) Lukens, W. W.; Magnani, N.; Booth, C. H. Inorg. Chem. 2012, 51, 10105 .

(25) Abragam, A.; Bleaney, B Electron Paramagnetic Resonance of Transition Ions; Clarendon Press: Oxford, 1970.

(26) Byers, P. K.; Canty, A. J.; Skelton, B. W.; Traill, P. R.; Watson, A. A.; White, A. H. Organometallics 1992, 11, 3085.

(27) Markies, B. A.; Canty, A. J.; Boersma, J.; van Koten, G. Organometallics 1994, 13, 2053. 